\title{
Effects of postnatal corticosterone treatment on reproductive development in the rat
}

\author{
Barbara B. Turner* and Anna Newman Taylor \\ Brain Research Institute and Department of Anatomy, \\ University of California School of Medicine, Los Angeles, California 90024, U.S.A.
}

\begin{abstract}
Summary. Reproductive development was studied in rats in which corticosterone ( $25 \mathrm{mg} / 100 \mathrm{~g}$ body wt) mixed with an equal amount of cholesterol was implanted i.p. at Days 3, 6, 12 or 18 after birth. Vaginal perforation in rats treated on Days 12 or 18 was advanced by 10 days but reproductive function in the treated animals was generally disrupted. A variable incidence of persistent vaginal oestrus was observed in adult females given implants on Days 3 and 6, and of prolonged vaginal dioestrus in those treated on Days 12 or 18. All treated females had lordosis quotients lower than those of untreated controls, the effect being most pronounced at the earlier ages of treatment. The results are believed to indicate two periods in reproductive development which are differentially affected by corticosterone.
\end{abstract}

\section{Introduction}

It is generally recognized that the expression of adult male patterns of gonadotrophin secretion and sexual behaviour in the rat depends on the presence of gonadal hormones during a critical period of neuronal development (Gorski, 1973). Analogous organizational effects on the brain-pituitaryadrenal axis by glucocorticoids and ACTH administration have been reported (Krieger, 1972, 1974; Lorenz, Branch \& Taylor, 1974; Turner \& Taylor, 1976). Corticosterone, the predominant glucocorticoid in the rat, differentially alters pituitary-adrenal function: transient and permanent lowering of plasma corticosterone levels were found in animals treated during the 1st week after birth and attenuation of diurnal fluctuations in plasma corticosterone was produced by treatment on Day 18 of age (Turner \& Taylor, 1976).

It has been demonstrated that reproductive development can be impaired by systemic treatment of immature mice with ACTH (Christian, 1964a,b; Jarrett, 1965) or by hypothalamic implants of cortisol in immature rats (Smith, Johnson, Weick, Levine \& Davidson, 1971). Since treatment in these experiments did not commence before 22 days of age, it was of interest to determine the effects of earlier hormonal exposure. We therefore investigated the reproductive development of the animals involved in our study of pituitary-adrenal function following sustained elevation of corticosterone in the absence of increased ACTH production. A preliminary report of this study has appeared (Turner \& Taylor, 1975).

\section{Materials and Methods}

Animals and treatment. Experimental animals consisted of the offspring of multiparous Long-Evans rats received when 8-10 days pregnant from Simonson Laboratories (Gilroy, California). Animals were housed under conditions of controlled temperature and illumination (lights on from 04.00 to $18.00 \mathrm{~h}$ ) and with permanent access to Purina Rat Chow and water. Cages were inspected twice daily for litters. Young found in the morning were considered to be 1 day old, those found in the evening as being 0 days. On Day 2 the young were removed and randomly cross-fostered, each litter being limited to a maximum of 5 males and 5 females.

\footnotetext{
* Present address: Mental Health Research Institute, University of Michigan, Ann Arbor, Michigan 48109. U.S.A.
} 
Pellets composed of equal amounts of corticosterone acetate (B grade, Calbiochem, San Diego, California) and cholesterol were fragmented and implanted intraperitoneally on Days 3, 6, 12 or 18 to give an implant of $25 \mathrm{mg}$ corticosterone acetate $/ 100 \mathrm{~g}$ body weight, accurate to the nearest $0.5 \mathrm{mg}$. According to the supplier, no androgens or oestrogens were chromatographically demonstrable in the corticosterone acetate. Control animals were untreated. Litters were left undisturbed until weaning on Day 25, and were then housed 2-4 to a cage according to sex and day of treatment. At various times after weaning, the animals were tested for pituitary-adrenal function (Turner \& Taylor, 1976) and open-field activity (Turner \& Taylor, 1975).

Intraperitoneal implantation of similar pellets in adrenalectomized weanling rats produced an elevation of $49 \mu \mathrm{g}$ corticosterone $/ 100 \mathrm{ml}$ plasma, determined fluorometrically by the method of Glick, Von Redlich \& Levine (1964), within $2 \mathrm{~h}$; the levels declined exponentially thereafter to less than $10 \mu \mathrm{g} / 100 \mathrm{ml}$ at 4 days. The implantation procedure itself, using only cholesterol, produced little or no elevation in plasma corticosterone at any of the treatment ages (Turner \& Taylor, 1976) when measured $2 \mathrm{~h}$ or later after operation.

Vaginal perforation and smears. Starting on Day 25, rats were examined twice daily for perforation of the vaginal membrane. The day of vaginal opening was taken as the first day of full opening, except for those females in which initial opening was followed by 2 or more days of vaginal closure; if a cornified smear was obtained only at re-opening, perforation was considered as occurring on this date. Vaginal smears were taken daily from the time of vaginal opening until Day 42, and again from Day 55 until autopsy.

A smear was scored as 'oestrous' only if fully cornified epithelial cells predominated. Occasionally, no pro-oestrous smear was detected before oestrus; in these cases, the first smear with cornified cells was scored as 'pro-oestrous'. A vaginal cycle was considered to begin with pro-oestrus and to continue until the next pro-oestrous smear. In the period immediately following vaginal opening, the presence of cornified cells for 8 or more consecutive days was scored as 'prolonged oestrus'; the presence of dioestrous smears for at least 5 consecutive days was considered to be 'prolonged dioestrus'. In adults, the presence of cornified cells in smears for 12 or more consecutive days was regarded as 'persistent vaginal oestrus'.

Lordosis quotients. The response of females at 74-86 days of age to mounting by an experienced, vigorous male was tested between 20.00 and $01.00 \mathrm{~h}$ on the night after a pro-oestrous smear. Because some females with 5 -day cycles had 2 days of vaginal oestrus, those with an initially poor response were retested the following night. Animals with highly irregular cycles or not exhibiting clear vaginal oestrus were tested for 5 nights and the highest score taken. On the basis of 25 mounts by a male, a lordosis quotient $(\mathrm{LQ})$ was calculated for each female $(\mathrm{LQ}=($ no. of lordoses $/ 25$ mounts $) \times 100$ ). This number of mounts could not be obtained for unresponsive animals and such females were tested for 30 min or a minimum of 10 mounts. Females were killed within $18 \mathrm{~h}$ of mating, confirmed by the presence of a vaginal plug or spermatozoa in the smear.

Autopsy. Animals were killed by an overdose of Nembutal, males between Days 73 and 80 , females between Days 75 and 87 . The abdominal organs, particularly the ovaries and uteri, were checked for possible damage resulting from the implantation procedure: 1 animal with severe damage was excluded from all reproductive measurements, 3 females with less severe damage were excluded only from the ovarian weight analysis. The wet weight of the gonads was determined to the nearest $0.1 \mathrm{mg}$ after uniform blotting. The gonads from representative animals of both sexes were fixed in Bouin's solution for subsequent histological examination.

Statistics. For all multiple comparisons against untreated controls, Student $t$-statistics were calculated and the joint significance levels of Dunnett (1964) were applied.

\section{Results}

Ages at vaginal opening. As shown in Table 1, the age at vaginal opening of the animals given implants on Days 3 or 6 did not differ from that of the untreated controls but treatment on Days 12 or 18 resulted in very early opening.

Vaginal cytology, Days 25-42. There were marked differences of the vaginal smear patterns in the 
Table 1. Mean \pm S.E.M. age of vaginal perforation of female rats treated with corticosterone implants

\begin{tabular}{lccccc}
\hline & & \multicolumn{4}{c}{ Day implant given } \\
\cline { 3 - 6 } & Control & 3 & 6 & 12 & 18 \\
\hline No. of rats & 17 & 15 & 10 & 21 & 17 \\
Age at vaginal opening (days) & $37.6 \pm 0.6$ & $35.9 \pm 0.9$ & $36.5 \pm 0.8$ & $27 \cdot 8 \pm 0 \cdot 5^{*}$ & $28 \cdot 0 \pm 0.8^{*}$ \\
\hline
\end{tabular}

* Significantly different compared with controls, $P<0.01$.

groups. All the control females cycled normally: 10/13 surviving females showed full cornification within I day of vaginal opening and no prolonged oestrous or dioestrous periods were observed.

Nine of 11 females treated on Day 3 showed prolonged dioestrus and the other two had irregular cycles. Females treated on Day 6 exhibited a similar though less well defined trend: of 10 animals, 3 had normal cycles and 5, prolonged dioestrus. Treatment on Day 12 resulted in prolonged vaginal oestrus in 5 of 20 animals, prolonged dioestrus in 9 and normal cycles in 3 . Of the 12 females implanted with steroid on Day 18, 8 showed prolonged vaginal oestrus (up to 15 days), 3 had irregular cycles and only 1 female cycled normally.

V'aginal cytology, Days 55-87. In all the treated groups there was an increase in the variance of cycle lengths $(P<0.001)$, and the effect of treatment on vaginal cornification (oestrus) appeared to be biphasic, according to the age of treatment (Table 2).

Table 2. The responses (between Days 55 and 87 ) of female rats treated with corticosterone after birth

\begin{tabular}{|c|c|c|c|c|c|}
\hline \multirow[b]{2}{*}{$\begin{array}{c}\text { Age at } \\
\text { treatment }\end{array}$} & \multirow[b]{2}{*}{$\begin{array}{l}\text { No. of } \\
\text { animals }\end{array}$} & \multirow[b]{2}{*}{$\frac{\text { Days in oestrus }}{\text { days smeared }} \times 100$} & \multicolumn{2}{|c|}{ No. of females with } & \multirow{2}{*}{$\begin{array}{c}\text { No. of } \\
\text { animals without } \\
\text { corpora lutea }\end{array}$} \\
\hline & & & $\begin{array}{l}\text { Normal } \\
\text { cycles }\end{array}$ & $\begin{array}{l}\text { Persistent } \\
\text { oestrus }\end{array}$ & \\
\hline Untreated & 16 & $31.7 \pm 1 \cdot 7$ & 15 & 0 & 0 \\
\hline Day 3 & 11 & $49 \cdot 5 \pm 5 \cdot 4^{*}$ & 2 & 5 & 4 \\
\hline Day 6 & 10 & $41 \cdot 4 \pm 7 \cdot 3$ & 3 & 2 & 2 \\
\hline Day 12 & 17 & $32 \cdot 3 \pm 2 \cdot 2$ & 7 & 0 & 2 \\
\hline Day 18 & 16 & $24 \cdot 1 \pm 2 \cdot 2 \dagger$ & 6 & 0 & 4 \\
\hline
\end{tabular}

Values (mean \pm S.E.M.) significantly different from those of untreated control animals: ${ }^{*} P<0.01, \dagger P<0.05$.

The number of days of vaginal oestrus was greatest in the females treated on Day 3 and the incidence of persistent vaginal oestrus was also high. The general pattern before the onset of persistent vaginal oestrus was an increase in cycle length accompanied by an increase in the duration of oestrus. In the females treated on Day 6, cycles generally became more irregular with increasing age, some tending toward lengthened oestrus, some toward lengthened dioestrus. The females implanted with steroid on Days 12 or 18 frequently failed to develop fully cornified epithelial cells and tended to have long cycles, e.g. $4.91 \pm 0.09$ days in the Day-18 females compared with $4.43 \pm 0.15$ in the controls $(P<0.05)$.

All females that had exhibited persistent vaginal oestrus as adults had previously shown prolonged dioestrus when younger. All the females, except one, that had not developed full cornification as adults had shown prolonged vaginal oestrus following vaginal opening.

Lordosis quotients. These are given in Table 3. Although females in all treated groups showed a significant decrease in sexual responsiveness, the reduction was more pronounced in the animals receiving steroid implants at the earlier ages. Previous vaginal cycle history did not reliably predict sexual responsiveness. Of the treated animals with normal cycles, over half scored less than $50 \%$ while females in which full cornification failed had higher mean scores than those with normal cycles. Females with persistent vaginal oestrus had consistently low scores, the highest being only $32 \%$. 
Table 3. Lordosis quotients (mean \pm S.E.M.) of female rats treated with corticosterone

\begin{tabular}{lcc}
\hline $\begin{array}{l}\text { Age at } \\
\text { treatment }\end{array}$ & $\begin{array}{c}\text { No. of } \\
\text { animals }\end{array}$ & Lordosis quotient \\
\hline Untreated & 16 & $95 \cdot 9 \pm 1 \cdot 8$ \\
Day 3 & 11 & $22 \cdot 5 \pm 9 \cdot 7^{*}$ \\
Day 6 & 7 & $46 \cdot 3 \pm 4 \cdot 2^{*}$ \\
Day 12 & 11 & $54 \cdot 0 \pm 9 \cdot 6^{*}$ \\
Day 18 & 13 & $67 \cdot 1 \pm 10 \cdot 2 \dagger$ \\
\hline
\end{tabular}

* Significantly different from control value, $P<0.01$.

† Significantly different from control value, $P<0.05$.

$\ddagger$ See text.

Table 4. Mean \pm S.E.M. weight of the gonads of rats treated with corticosterone implants

\begin{tabular}{|c|c|c|c|c|c|}
\hline & \multirow[b]{2}{*}{ Control } & \multicolumn{4}{|c|}{ Day implant given } \\
\hline & & 3 & 6 & 12 & 18 \\
\hline \multicolumn{6}{|l|}{ Males } \\
\hline No. & 16 & 10 & 11 & 16 & 11 \\
\hline Testicular wt (mg) & $2944 \pm 46 \dagger$ & $2394 \pm 162 \dagger$ & $2337 \pm 68 \dagger$ & $2573 \pm 103 \dagger$ & $2518 \pm 109 \dagger$ \\
\hline Body wt (g) & $336.6 \pm 6.9$ & $301 \cdot 3 \pm 14 \cdot 1$ & $314 \cdot 4 \pm 7 \cdot 4$ & $306 \cdot 3 \pm 7 \cdot 6^{*}$ & $278.7 \pm 15 \cdot 0^{*}$ \\
\hline \multicolumn{6}{|l|}{ Females } \\
\hline No. & 17 & 12 & 8 & 15 & 11 \\
\hline Ovarian wt (mg) & $84 \cdot 3 \pm 3 \cdot 5$ & $58 \cdot 2 \pm 6 \cdot 1 \dagger$ & $67 \cdot 4 \pm 5 \cdot 0^{*}$ & $66 \cdot 1 \pm 2 \cdot 7 \dagger$ & $67 \cdot 3 \pm 2 \cdot 7 \dagger$ \\
\hline Body wt (g) & $220 \cdot 7 \pm 3 \cdot 4$ & $226 \cdot 3 \pm 11 \cdot 0$ & $204.9 \pm 6 \cdot 5$ & $213 \cdot 5 \pm 5 \cdot 2$ & $224 \cdot 6 \pm 6 \cdot 5$ \\
\hline
\end{tabular}

Gonadal weights and histology. The weights of ovaries and testes are shown in Table 4. No testicular abnormalities were observed at autopsy. Histological examination of testicular sections from representative animals from each of the groups revealed no evidence of atrophy or impairment of spermatogenesis, but in all treated groups localized pockets of Sertoli-cell hyperplasia were noted in several peripheral seminiferous tubules. Isolated instances of a tubule with germ cell aplasia were observed in animals treated on Days 3,12 or 18.

Fresh corpora lutea were present in both ovaries of all control females, in $45 \%$ of females treated on Day 3, in $67 \%$ treated on Day 6, in $75 \%$ on Day 12 and $69 \%$ of those treated on Day 18 . Absence of corpora lutea was correlated with the absence of dilated ampullae, tubal ova and vaginal plugs. The polyfollicular ovary syndrome was histologically verified in animals showing persistent vaginal oestrus; in all but one such female, corpora lutea were absent. In rats which had shown prolonged vaginal cornification, early stages of the syndrome were observed. Animals in which full vaginal cornification was absent had ovaries characterized by large corpora lutea, interstitial cell hyperplasia, and many atretic follicles.

\section{Discussion}

These results indicate that postnatal corticosterone treatment has effects on reproductive development, some of which are specific to the age at which the steroid is implanted. The effects of steroid implantation during the first week after birth were distinct from those observed in rats treated at later ages. The persistent vaginal oestrus which occurred in animals treated on Days 3 or 6 was similar to the effect produced by androgen (Gorski, 1971). As with androgen, the younger age group 
was more severely affected, and after Day 6 the effect was no longer observed. Administration of glucocorticoids (Selye \& Friedman, 1940; Takasugi, 1953) and cholesterol (Takasugi, 1953) in high doses over a prolonged period has been reported to have effects similar to those induced by androgen. The action of corticosterone-cholesterol implanted neonatally was clearly inhibitory: cycles immediately following vaginal opening were disrupted, persistent vaginal oestrus ensued, and polyfollicular ovaries of significantly low weight were found at death. At later ages, steroid implantation also had a general inhibitory effect on ovarian function, e.g. abnormal cycling, low ovarian weight and, in some animals, sterility, despite the occurrence of early vaginal opening.

The mechanism of induction of early vaginal perforation by corticosterone-cholesterol implantation appears to be different from that induced by androgen. The effectiveness of neonatal androgen treatment in inducing precocious vaginal opening and persistent vaginal oestrus seems to end on Day 11 after birth (Lobl \& Gorski, 1974). Moreover, the persistent vaginal oestrus which characterizes effective androgenization was not observed in those animals in the present study in which early vaginal opening occurred. These animals exhibited prolonged dioestrus, a characteristic of neonatal oestrogen treatment (Flerko, 1971). Exposure of rats in infancy to extrinsic stimulation, such as daily handling during the entire preweaning period, also produces precocious vaginal opening (Morton, Denenberg \& Zarrow, 1963). Although our rats were handled only on the day of implantation, such stimulation cannot be excluded as a contributing factor. However, the present results suggest that corticosterone treatment may differentially sensitize infant rats, rendering them more susceptible to stimulation-induced early vaginal opening during the later part of the preweaning period.

Gonadal dysfunction would be expected to reduce sexual responsiveness but because it was considered to be more important to obtain adrenal weights from intact animals in the present study females were not tested following ovariectomy and oestrogen-progesterone therapy. However, the lordosis quotients of the rats treated with corticosterone and cycling normally were no higher than those of rats with irregular cycles, suggesting that the regulation of sexual behaviour may include elements in addition to those involved in the regulation of gonadal function. Pfaff \& Zigmond (1971) have shown that more than one hormone-receptor system is involved in the reduction of sexual responsiveness associated with early androgen treatment. Sexual behaviour has been shown to be facilitated by progesterone at the level of the mesencephalic reticular formation (Ross, Claybaugh, Clemens \& Gorski, 1971), a region in which corticosteroid-sensitive neurones have also been demonstrated (Dafny, Phillips, Taylor \& Gilman, 1973). It is therefore possible that sexual responsiveness can be reduced by an inhibitory effect of corticosterone on the development of sensitive structures within the reticular formation or other brain regions.

The age-dependent results of corticosterone treatment of the rats in the present study may be related to the observation that the effects of glucocorticoid administration on maturation of the central nervous system are reversed after postnatal Day 8 (Vernadakis \& Woodbury, 1971). Likewise, the correspondence between the effects of corticosterone implantation on the reproductive and adrenal systems (Turner \& Taylor, 1976) may not becoincidental : the inhibition produced by treatment on Day 3 was more pronounced than that on Day 6, while the inhibition observed after treatment at later ages was different, and 18-day-old rats were more sensitive than 12-day-old animals.

It is evident that postnatal implantation of corticosterone can produce a variety of age-specific effects on reproductive development and behaviour as well as on pituitary-adrenal function. Although the extent of central actions of the hormone in producing these effects is uncertain, it would seem probable that glucocorticoid-sensitive neural elements influence several systems, and that the developing neural substrates are particularly sensitive. High concentrations of corticosterone in the rat may block appropriate differentiation of the hypothalamic or extrahypothalamic sites involved in positive feedback control of gonadotrophin secretion.

This study was supported by grants from NIH (NS 09122) and NSF (GB 33474), an AEC predoctoral fellowship to B.B.T. and an NIMH Research Scientist Development Award (KO2-MH70484) to A.N.T. We should like to express our appreciation to Ms Berrilyn Branch for extremely competent technical assistance. 


\section{References}

Christian, J.J. (1964a) Effect of chronic ACTH treatment on maturation of intact female mice. Endocrinology 74, 669-679.

Christian, J.J. (1964b) Actions of ACTH in intact and corticoid maintained adrenalectomized female mice with emphasis on the reproductive tract. Endocrinology 75, 653-669.

Dafny, N., Phillips, M.I., Taylor, A.N. \& Gilman, S. (1973) Dose-effects of cortisol on single unit activity in hypothalamus, reticular formation and hippocampus of freely behaving rats correlated with plasma steroid levels. Brain Res. 59, 257-272.

DUNNETT, C.W. (1964) New tables for multiple comparisons with a control. Biometrics 20, 482-491

Flerko, B. (1971) Steroid hormones and the differentiation of the central nervous system. In Current Topics in Experimental Endocrinology, pp. 41-80. Eds L. Martini \& V. H. T. James. Academic Press, New York.

Glick, D., Von Redlich, D. \& Levine, S. (1964) Fluorometric determination of corticosterone and cortisol in $0.02-0.05$ milliliters of plasma or submilligram samples of adrenal tissue. Endocrinology $74,653-655$.

GoRskı, R.A. (1971) Gonadal hormones and the perinatal development of neuroendocrine function. In Frontiers in Neuroendocrinology, pp. 237-290. Eds L. Martini \& W. F. Ganong. Oxford University Press, New York.

GoRski, R.A. (1973) Perinatal effects of sex steroids on brain development and function. Prog. Brain Res. 39, 149-162.

JARRETT, R.J. (1965) Effects and mode of action of ACTH upon the reproductive tract of the female mouse. Endocrinology 76, 434-440.

KRIEGER, D.T. (1972) Circadian corticosteroid periodicity: critical period for abolition by neonatal injection of corticosteroid. Science, N.Y. 178, 12051207.

KRIEGER, D.T. (1974) Effect of neonatal hydrocortisone on corticosteroid circadian periodicity, responsiveness to ACTH and stress in prepubertal and adult rats. Neuroendocrinology 16, 355-363.
LoBL, R.T. \& GoRsKI, R.A. (1974) Neonatal intrahypothalamic androgen administration: the influence of dose and age on androgenization of female rats. Endocrinology 94, 1325-1330.

LORENZ, R.L., BRANCH, B.B. \& TAYLOR, A.N. (1974) Ontogenesis of circadian pituitary-adrenal periodicity in rats affected by neonatal treatment with ACTH. Proc. Soc. exp. Biol. Med. 145, 528-532.

Morton, J.R.C., Denenberg, V.H. \& Zarrow, M.X. (1963) Modification of sexual development through stimulation in infancy. Endocrinology 72, 439-442.

Pfaff, D.W. \& Zigmond, R.E. (1971) Neonatal androgen effects on sexual and nonsexual behavior of adult rats tested under various hormone regimes. Neuroendocrinology 7, 129-145.

Ross, J., Claybaugh, C., Clemens, L.G. \& Gorski, R.A. (1971) Short latency induction of estrus behavior with intracerebral gonadal hormones in ovariectomized rats. Endocrinology 89, 32-38.

Selye, H. \& Friedman, S.M. (1940) The action of various steroid hormones on the ovary. Endocrinology 27, 857-866.

Smith, E.R., Johnson, J., Weick, R.F., Levine, S. \& Davidson, J.M. (1971) Inhibition of the reproductive system in immature rats by intracerebral implantation of cortisol. Neuroendocrinology 8, 94-106.

Takasugi, N. (1953) Einflüsse von Progesteron, Desoxykortikosteronacetat und Cholesterin auf die Ovarien der neugeborenen, weiblichen Ratten. Annotnes zool. jap. 26, 52-56.

TURNER, B.B. \& TAYLOR, A.N. (1975) Postnatal corticosterone treatment : effect on reproductive development and open field behavior. Fedn Proc. Fedn Am. Socs exp. Biol. 34, 302.

TURNer, B.B. \& TAYloR, A.N. (1976) Persistent alteration of pituitary-adrenal function in the rat by prepubertal corticosterone treatment. Endocrinology 98, 1-9.

VERNADAKIS, A. \& WoOdBuRY, D.M. (1971) Effects of cortisol on maturation of the central nervous system. In Influence of Hormones on the Nervous System, pp. 85-97. Ed. D. H. Ford. Karger, Basel. 